ric furnace. When the motal fu ses it gets saturated with carbon, orming a carburet mixed with free carbon, which after solidifcation exists in the form of swelling or true graphite. It is separated by aqua regia. The residue consists of slate-grey hexagonal crystals of density 2.06 to 2.08 , burning in a current of oxygen at $575^{\circ}$. From $400^{\circ}$ upwards it swells like mercury sulpho-cyanide. It is not attacked by fused nitrate of potassium, chromic acid, or hot sulphuric acid, but is rapidly attacked by warm iodic acid and fused sodium carbonate. The swelling up is attributed to the sudden liberation of heated gas due to the decomposition of a very small quantity of graphitic oxide produced under the influence of nitric acid at the expense of a trace of amorphous graphite mixed with the crystallised variety, and more easily attacked than the latter.-Researches on samarium, by M. Lecoq de Boisbaudran. - The pancreas and the nerve centre regulating the glycemic function; experimental demonstrations derived from a comparison of the effects of a removal of the pancreas with those of bulbary section, by MM. A. Chauveau and M. Kaufmann. Medullary section, preceded or followed by bulbary section, produces exactly the same effects as medullary section preceded or followed by the removal of the pancreas. As regards, therefore, the physiological action exerted upon the sugar-forming apparatus, this last operation behaves exactly like the bulbary section. Now the latte determines the super-activity of the liver by suppressing the transmission of the influence of an inhibitory centre situated in the medulla oblongata. As a necessary result, the removal of the pancreas acts in an analogous way in producing hyperglycemia and glycosuria. This operation amounts to the annihilation of the centre controlling the glycogenic function. Hence the pancreas acts upon this function by exciting the activity of this inhibitory centre, and probably also by influencing the exciting centre, which is, on the other hand, checked in its activity by the products of internal pancreatic secretion poured into the blood. The results of the whole experimental investigation on the pathogeny of diabetes are embodied in sixteen propositions,-On the distribution in latitude of the solar phenomena observed at the Royal Obser. vatory of the Roman College during the fourth quarter of 1892 , by M. P. Tacchini, - Photography of the solar corona apart from total eclipses, by M. George E. Hale.-On electric waves along fine threads; calculation of the depression, by M, Birkeland. On initial capacities of polarisation, by M. E. Bouty.-Influence of frequency upon the physiological effects of alternating currents, by M. d'Arsonval.-Measurement of large differences of phase in white light, by M. P. Joubin. A new method of rendering visible the fringes produced by two interfering systems of waves consists in placing an anisotropic compensator upon both the groups which have traversed the interference apparatus. This compensator then receives polarised light which, before being analysed, passes through a plate of quartz with its principal section at an angle of $45^{\circ}$ to the plane of polarisation. Such an arrangement has been carried out in one of Fizeau's apparatus for measuring expansions. It reads direct to $\frac{1}{50}$ of a micron. On spherical aberration of the human eye; measurement of senilism of the crystalline, by M. C. J. A. Leroy. The mean aberration is a function of the age which grows slowly in young people and very rapidly after mature age, tending towards a maximum in old age. The spherical aberration of the eye also depends principally upon the crystalline and notably upon the variability of its index of refraction. In young people this variability is rapid enough to sensibly correct the aberration. It decreases with age, and tends to a limiting value which it would have if the crystalline had a uniform index throughout.

-Electrical crucible for the laboratory, with directing magnet, by MM. E. Ducretet and L. Lejeune.-On a phenomenon of dissociation of sodium chloride heated in presence of a wall of porous earth, by M. de Sanderval.-On hydurilic and desoxyamalic acids, by M. C. Matignon. - Action of cotton upon sublimate absorbed in dilute solutions, by $\mathrm{M}$. Léo Vignon. - Influence of the alkalinity of blood upon the process of intra-organic oxidation provoked by spermine, by $M$. Alexandre Pœhl.-Production of sugar diabetes in the rabbit by the destruction of the pancreas, by M. E. Hédon. - Improvement of potato-culture for industrial and forage purposes in France, by M. Aimé Girard. - On the employment of ruthenium red in vegetable anatomy, by $\mathbf{M}$. Louis Mangin.-Permian fish fauna in France, by M. H. E. Sauvage.-On the manifestation, for more than six hundred years, of sudden variations of tempera

NO. I 222 , VOL. 47$]$ ture on fixed dates during the second fortnight of January, by M. Dom D. Démoulin.-Destruction of trees and public health, by M. J. Jeannel.

\section{BOOKS, PAMPHLETS, and SERIALS RECEIVED.}

Books.-Laws and Properties of Matter: R. T. Glazebrook (K. Paul).British Fungus Flora, vol. 2: : G. Massey (Bell). - Text-book of Comparative Geolugy : Dr. E. Kayser, translated and edited by P. Lake (Sonnenschein). Beitrige zur Diologie und Anatomie der Iianen. Zweiter Theil :- - Beiträge Complètes de Christian Huygens, vol. 5 (La Haye, M. Nijhoff). - Statistics of the Colony of Tasmania, $189 \mathrm{~g}$ (Tasmania).--Meteorological Observations of the Colony of Tasmania, 189r (Tasmania).--Meteorological Observations made at the Adelaide (Ohservatory, \&c., 1890 (Adelaide). - Lehrbuch der

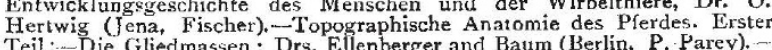
Teil:-Die Gliedmassen: Drs. Ellenberger and Baum (Berlin, P. Parey). Distribution de la Vapeur: A. Madamet (Paris, Gauthier-Villars) - Le La
P. Langlois (Paris, Gauthier-Villars). - Universal Atlas. Part 25 (Cassell). Langlois (Paris, Gauthier-Villars), - Universal Atlas. Part ${ }^{25}$ (Casseli). PAMPHLETS.-Diagrams of Isothermal Lines of New South Wates.- Hailstorms : H. C. Russell. - Das Cenetische System der Chemischen Elemente : W. Preyer (Berlin, Friedländer), - Further Studies of Yuccas and their Pollinaion: W. Trelease (St. Louis, Mo.).-.Museums Association, Report of Procceding;, \&c., at the Third Anmual Can

District of Columbia : E. Ingle (Balt.). SERIALs.-Memoirs and Proceedings of the Manchester Literary and
philosophical Society, vol. 7 , No. I (Manchester). - Journal of the College Pr Science, Imperial University, Japan, vol. v., part 3 (Tōkyō).
of

\section{CONTENTS.}

PAGE:

Electromagnetic Waves. By H. L. . . . . . . 505

The Great Sea-Serpent . . . . . . . . 506

Public Health. By Dr. H, Brock . . . . . . 507

Our Book Shelf:-

Robinson: "The English Flower Garden: Style, Position, and Arrangement, followed by a Descrip. tion of all the Best Plants for it, their Culture and Arrangement" . . . . . . . . . . 50

Tones : "Logarithmic Tables" . . . . . . . . 508

Bell : "Catalogue of the British Echinoderms in the British Museum (Natural History)". . . . . 508 Letters to the Editor:-

The Hatching of a Peripatus Egg.--Arthur Dendy . 508

A Simple Rule for finding the Day of the Week corresponding to any given Day of the Month and Year. -H. W. W.

"Roche's Limit."-G. R. . . . . . . . . 500

The Ordnance Survey and Geological Faults.-Jas. Durham

The Discovery of the Potential-OOttavio Zonott Bianco; Dr, E. J. Routh, F.R.S.

Van't Hoff's "Stereochemistry."-Prof. Percy F. Frankland, F.R.S. ; Prof. F. R. Japp, F.R.S Standard Barometry. (Illustrated.)-Dr. Frank Waldo

Motion of a Solid Body in a Viscous Liquid.-A. B.

Basset, F.R.S. . . . . . . . . 512 Science in the Public Schools and in the Scientific Branches of the Army ......... $5 \mathrm{I}_{3}$ Climbing Plants. By W. Botting Hemsley, F.R.S. 5 I4 Clapham Junction and Paddington Railway . . . 515

Notes ........ 515

Our Astronomical Column:-

Comet Holmes (1892 III.) . . . . . . . . . . 518

Wolsingham Observatory, Circular No. 34 . . . . 518

Jupiter and his Satellites . . . . . . . . 5 I8

The Horizontal Pendulum . . . . . . . . 519

The Rising and Settings of Stars . . . . . . . 519

Geographical Notes ......... 519

The Institution of Naval Architects . . . . . . 519

The Action of Glaciers on the Land . . . . . 52x

Further Studies on Hydrazine. By A. E. Tutton . 522

The International Congress of Prehistoric Archzology and Anthropology. By A. C. H. . . . 523

Scientific Serials ............. 524

Societies and Academies . . . . . . . . 526

Books, Pamphlets, and Serials Received .... 528 